\title{
ESPACIO Y PERSONAJES EN MISERICORDIA DE BENITO PÉREZ GALDÓS
}

\author{
Soraya Sádaba Alonso \\ Universidad de Zaragoza
}

\begin{abstract}
RESUMEN: En muchas de sus novelas, y especialmente en Misericordia, Galdós se sirve del espacio como una forma más de dotar de una mayor dimensión significativa a sus personajes. De este modo, será intencionado el emplazamiento de la acción de su obra en una zona concreta de Madrid, no sólo por su posible interpretación socio - histórica, sino también por una serie de implicaciones simbólicas que propician el reconocimiento de valores sociales y espirituales en la España finisecular.
\end{abstract}

ABSTRACT:In many of his novels, especially in Misericordia, Galdós makes use of space like another form to provide his characters with the greatest significant dimension. So it will be intentional to place the location of his book in a specific area of Madrid, not only because of its possible social and historical interpretation, but also because of a string of symbolic implications that cause the recognition of social and spiritual values in the Spanish turn of the century.

PALABRAS CLAVE: Misericordia; Galdós; personajes; espacio.

KEYWORDS: Misericordia; Galdós; characters; space.

\section{Hacia un espacio propio}

Sin duda alguna, es en Misericordia (1897) donde el espacio madrileño toma un cariz especial, convirtiéndose en valor intrínseco de los personajes, en tanto en cuanto no podríamos entender una persona como Benigna reflejada en otro ambiente, en otro espacio novelesco. Galdós disecciona no sólo la sociedad, sino también el espacio que la constituye, y nos dibuja una España decadente, donde la doble moralidad burguesa, con todas las hipocresías y bajezas, es la que rige los designios espirituales de la sociedad. De ahí que cada calle, plaza o costanilla pase a ser un ente orgánico y funcionen en la novela mecanismos de subjetivación del espacio en virtud de esquemas como exteriorinterior, arriba-abajo, Norte-Sur...

Esa realidad palpitante que sentimos cuando leemos descripciones de los barrios del otro lado del Manzanares, en la zona sur de Madrid, Galdós la buscó 
en sus recorridos por la ciudad, en sus paseos por las calles que poco a poco iban cobrando vida en su imaginación, como futuros 'ecosistemas' donde se desarrollaría la vida, pero la vida con mayúsculas, ese ajetreo continuado de los comerciantes que gritan los precios de sus productos, las mujeres hablando con avidez en pequeños grupos, los chiquillos harapientos que corretean entre la multitud... Este cuadro desgajado de realidad que encontraríamos por ejemplo en la calle de Toledo, nos sumerge de lleno en la vida popular, que al fin y al cabo parece 'más vida' que la que lleva la burguesía o clase media. De este modo, el espacio de Madrid pasa a convertirse en un ente ficticio más, que está presente en la configuración de la novela, un personaje que con la significación social de cada uno de sus barrios nos sirve de guía para el dibujo de los caracteres del resto de los protagonistas.

El afán por documentarse en los entresijos de la vida madrileña es un método que será aplicado para la elaboración de Misericordia, según se observa en las propias palabras del autor durante la inauguración de la Sección de Literatura del Ateneo:

"Ello es que no podía resistir la tentación de lanzarme a las calles en busca de una cátedra y enseñanza más amplias que las universitarias; las aulas de la vida urbana, el estudio y reconocimiento visual de las calles, callejuelas, angosturas, costanillas, plazuelas y rincones de esta urbe madrileña, que a mi parecer contenía copiosa materia filosófica, jurídica, canónica, económico-política y, sobre todo, literaria"1

Una vez tomados los datos históricos documentales, éstos son transformados para dar lugar a una ficción, estableciendo una espacialización peculiar dentro del devenir narrativo de la propia novela. Es decir, se puede distinguir claramente un espacio socio-histórico que nos permite situar a los personajes en un mundo concreto según vivan en el barrio de Salamanca o en el distrito de la Latina. Por otro lado, un aspecto ya habitual en la obra galdosiana como son los símbolos, adquiere gran protagonismo en Misericordia, y son especialmente significativos en lo que respecta al espacio². Además, Galdós aporta una mayor riqueza a sus obras, descubriendo el ámbito interior psicológico de los personajes, dentro del cual se albergan el sueño, la memoria o la imaginación ${ }^{3}$, que también son espacios a los que el autor es capaz de dar carta de naturaleza.

1. PÉREZ GALDÓS, Benito, 'Madrid', "Guía espiritual de España", Obras Completas. Novelas III/Misceláneas, Madrid, Aguilar, 1977, pág. 1268.

2. Este dotar de un significado simbólico a un espacio urbano que hasta hace bien poco había funcionado como un simple telón de fondo costumbrista, está presente en Galdós desde los inicios de su andadura novelística. Vid. BAKER, Edward, "En el café de Galdós: La Fontana de Oro", Materiales para escribir Madrid: literatura y espacio urbano, Madrid, Siglo XXI, 1991.

3. En este sentido se deben tener en cuenta las aportaciones de Gaston BACHELARD, La poética del espacio, México, Fondo de Cultura Económica, 1992. 
Por lo tanto, lo que pretendo con este artículo es mostrar cómo el espacio socio-histórico, el espacio simbólico y el espacio psicológico son utilizados por Galdós como técnicas para configurar su universo novelesco, de manera que cada uno aporta matices esenciales para la creación del contorno de los protagonistas, para la plasmación cabal de las ideas galdosianas sobre la caridad y cómo ésta se halla en el Madrid de las periferias. La conjunción de estos tres elementos dotan a Misericordia de una profundidad temática que subyace a una realidad más palpable, y entretejen una red de relaciones que tomando como centro neurálgico a Nina, se extienden a todos aquellos que la rodean.

\section{El espacio socio-histórico}

Ya se ha mencionado la especial significación que tiene la distribución de los personajes de ficción por todos los barrios de Madrid ${ }^{4}$. Algo tan evidente para los madrileños de fin de siglo como es la polaridad Norte-Sur que se percibe en su ciudad y que es sintomática de una escisión clara en el plano social y económico entre las gentes, va a ser aprovechada por Galdós para hacer un dibujo de sus personajes, evitando descripciones prolíficas. Esta distinción se explicita en la novela a través de la curiosa figura del señor Ponte, que sobrevive como puede de trabajillos más o menos decorosos, y se ve en la tesitura de moverse por los barrios del Sur, sin pisar el Centro y el Norte, para así evitar que cualquier conocido, sabedor de las antiguas glorias de Frasquito, le vea en la comprometedora situación de llevar unos zapatos y unos vestidos indignos de su persona.

En Misericordia la acción se desarrolla plenamente en los barrios marginales sin cruzar los límites de la Puerta del Sol, de manera que la pequeña burguesía, el pueblo y los indigentes, constituyen el sustrato sociológico de la novela. Cabe destacar al respecto, que a partir de Miau, es cuando los emplazamientos de las Novelas Contemporáneas tenderán a ser marginales y excéntricos, y la cercanía

4. Son muchos los trabajos que se han dedicado al Madrid de Galdós, aunque por el momento todavía parece faltar un estudio general completo que abarque todos los planos significativos de la ciudad capital. Sin embargo conviene tener en cuenta libros clásicos como los de Pedro de RÉPIDE, Las calles de Madrid, Ed. La Librería, 1971; H. PEÑASCO y C. CAMBRONERO, Las calles de Madrid. Noticias, tradiciones y curiosidades, Ediciones Guillermo Blázquez, 1889; A. CAPMANY, Origen histórico y etimológico de las calles de Madrid, Ediciones Guillermo Bázquez,1863, y otros más actuales como los de Carlos PLA, El Madrid de Galdós, Madrid, El Avapiés, 1987; Ramón HIDALGO, Madrid galdosiano, Madrid, La Librería, 1990; VVAA, Madrid en Galdós, Galdós en Madrid, Madrid, Consejería de Cultura, Dirección General de Patrimonio Cultural, 1988; Federico C.SAINZ DE ROBLES, El Madrid de Galdós, o Galdós, uno de los Cuatro Grandes, no madrileños de Madrid, Madrid, Instituto de Estudios Madrileños, 1967. 
al Madrid del centro, implicará un acercamiento un tanto irónico 5 . La única mención a un lugar del Norte es la Plaza de Olavide en el distrito de Chamberí. Pero esta mención de un lugar mejor situado, se ve empañada por la referencia a un espacio destinado al albergue de gente sin techo: "y, si esta noche no me da cobijo la Ricarda en el cajón de Chamberí, tendré que quedarme al santo raso" (pág. 79) ${ }^{6}$. Las bolsas de pobreza habituales son las que encontramos en los distritos de la Latina, el Hospital, o el más miserable de todos, la Inclusa, aunque posteriormente estos núcleos van extendiéndose más allá de los Ensanches, en barrios populares como el de la Guindalera. Aparte de los ya mencionados barrios de la zona sur, se encuentran también los barrios de la periferia que rodean a la ciudad y que poseen las mismas condiciones de mendicidad, insalubridad y enfermedades. Serían los barrios que forman el cinturón, situados cerca del Manzanares y que aparecen cuando Nina y Almudena descienden a los infiernos de las Cambroneras.

Son muchos los lugares de distinta índole que vamos descubriendo en el ir y venir de Nina, y que Galdós se encargará de describir con toda minuciosidad, hasta tal punto que en muchas ocasiones la crítica las ha calificado de escenas goyescas. A pesar de que prima una visión detallista, con muy buen criterio seleccionará aquellos detalles que son más puntuales y significativos, buscando la reacción del lector al plasmar una gran actividad humana. De este modo, sólo un apunte, un adjetivo, el reflejo casi cinematográfico de una secuencia es lo que servirá para que el lector se sienta completamente impregnado de ese mundo de desheredados. Las casas de vecindad hacen acto de presencia en la obra, y también las llamadas casas de dormir, donde se alquilaban camas a un módico precio. Normalmente estaban situadas en las rondas, repartidas por toda la ciudad. Los inquilinos eran gente que habitaban una casa que les era imposible pagar, por lo que compartían el lugar con otras familias o recurrían a subalquilar las habitaciones o las camas a personas que pertenecían al hampa madrileña. En este caso, es mejor dejar hablar a Galdós, llevándonos al pésimo habitáculo de la calle del Mediodía Grande en el que Ponte maldormía:

"...entraba la diligente anciana en la fementida tabernuca que 'da la cara' al público en el 'establecimiento' citado (...) por estrecha puertecilla, bien disimulada entre los estantes llenos de botellas y garrafas que había detrás del mostrador. Como grieta que da paso al escondrijo de una anguila, así era

5. ANDERSON, Farris, "Madrid y el espacio de Miau", Cuadernos Hispanoamericanos, Núm. 521, noviembre, 1993, pág. 23-36.

6. Todas las citas serán tomadas de la edición de Misericordia de Luciano GARCÍA LORENZO (Madrid, Cátedra, 1998). 


\section{ESPACIO Y PERSONAJES EN MISERICORDIA DE BENITO PÉREZ GALDÓS}

la puerta (...) agachándose se escurrieron por el agujero que hacía las veces de puerta entre los estantillos del mostrador (...) Por un pasillo mal oliente y sucio llegaron a una cocina donde no se guisaba. Fogón y vasares servía de depósito de botellas vacías, cajas desechas, sillas rotas y montones de trapos"(pág. 190-192).

Otros espacios interesantes y que llamaban de forma insistente la atención de Galdós, eran las tiendas y los cajones que se ponían en las calles y que procuraban escenas llenas de color a la vida madrileña. Dadas las continuas trapisondas en las que se tiene que ver Nina para poder sacar el trozo de carne a un real más barato, parece lógica la abundante mención de estos establecimientos. Por otra parte, si hacemos un censo de las parroquias, conventos, asilos, hospitales... que tienen cabida en Misericordia, vemos que es una nómina abundante y deja claro cuál es el ambiente en el que los personajes se van a mover. El lugar que más atención ha despertado por parte de la crítica es, sin duda, la Iglesia de San Sebastián 7 . Conviene recordar que en los escritores realistas era habitual comenzar la novela por la descripción del lugar donde se iba a desarrollar la acción. En el caso de esta narración, dicha afirmación se cumple parcialmente, puesto que la Iglesia de San Sebastián no es el espacio capital donde tienen lugar las peripecias de los protagonistas, sino que más bien hay un gran variedad de sitios por donde circulan los personajes. Ahora bien, es indudable que la descripción de la iglesia sirve para marcar un tono en el ambiente novelesco, y por lo tanto, esta pintura inicial se erige en visión totalmente representativa del mundo que rige los designios de la pobretería madrileña finisecular.

Desde el comienzo se nos dice que la parroquia tenía dos salidas ${ }^{8}$, una que daba a la calle de Cañizares, que permitía la visión de los barrios bajos y otra que daba a la Plaza del Ángel, emplazamiento de la clase mercantil, y que tuvo su punto aristocrático y de vida literaria. Para marcar todavía más esta dicotomía se funda

7. Pierre L. ULLMAN, "A Contrapuntal and Spenglerian Approach to Misericordia", Hispanic Review, Núm. 60 (3), summer 1992, p. 321-339; Virginia TOVAR MARTÍN, "La vida religiosa: las iglesias de Madrid", Madrid en Galdós, Galdós en Madrid, op. cit., pág. 139-162; Margarita O'BYRNE CURTIS, "Madrid o la locura del 'texto' urbano: la representación de la ciudad en la narrativa galdosiana", Studies in honor of Gilberto Paolini, ed. Mercedes Vidal, Newark, Delaware, Ed. Juan de la Cuesta, 1996, pág. 195-206.

8. "Traza Galdós con los primores de su pluma, en uno de sus libros, la fisonomía urbana y hasta topográfico-social de esta parroquia, especie de atalaya fronteriza, cuyas puertas ponen en comunicación al Madrid elegante con los barrios bajos, y cuyos muros son por mitad aristocráticos o plebeyos, como su feligresía.", Manuel MESONERO ROMANOS, "El arte en las iglesias de Madrid. San Sebastián", La Ilustracion Española y Americana, Año LVIII, Núm. XLV, 8 diciembre 1914, pág. 350. 
en la polaridad Norte-Sur, pero invirtiendo los valores que cabría esperar: "En la cara del Sur campea, sobre una puerta chabacana, la imagen barroca del santo mártir, retorcida, en actitud más bien danzante que religiosa; en la del Norte, desnuda de ornatos, pobre y vulgar, se alza la torre, de la cual podría creerse que se pone en jarras, soltándole cuatro frescas a la Plaza del Ángel" (pág. 62). La contradicción en la orientación de las puertas puede deberse a un juego de ironía galdosiana, en ese afán por los trucos de apariencia y engaño, de excepciones que confirmen la regla.

Hay también a lo largo de toda la novela, una serie de representaciones sintomáticas de recintos descritos minuciosamente y que son puntos clave en el texto, ya que es donde se albergarán los distintos protagonistas. Por eso, de un lado nos encontramos con la pintura de casas miserables como ocurre con la vivienda de Almudena, una casa de vecindad situada en la zona periférica de la Ronda de Toledo:

\footnotetext{
"...hallaron el parador de Santa Casilda, vasta colmena de viviendas baratas alineadas en corredores sobrepuestos. Éntrase a ella por un patio o corralón largo y estrecho, lleno de montones de basura, residuos, despojos y desperdicios de todo lo humano. El cuarto que habitaba Almudena era el último del piso bajo, al ras del suelo (...) Componíase la vivienda de dos piezas separadas por una estera pendiente del techo: a un lado la cocina, a otro la sala, que también era alcoba o gabinete, con piso de tierra bien apisonado, paredes blancas, no tan sucias como otras del mismo caserón o humana madriguera. Una silla era el único mueble, pues la cama consistía en un jergón y mantas pardas, arrimado todo a un ángulo. La cocinilla no estaba desprovista de pucheros, cacerolas, botellas,..." (pág. 91-92)
}

Estas palabras, u otras similares, aparecen en otras ocasiones, como en el momento en que Nina baja por la Puente de Toledo hacia el arrabal de las Cambroneras $^{9}$, y se encuentra con gitanos, niños en harapos que corren sin parar, animales macilentos... El tono que muestra la desolación del lugar se va agudizando según avanza en dirección a la Puente Segoviana, al mostrarse casa antiquísimas destartaladas, con techos derruidos, sin puertas ni ventanas,

9. Creo interesante echar un vistazo a la definición que da el Tesoro de Covarrubias de 'cambrón' y 'cambronera', ya que ejemplifica muy bien la significación simbólica que va a adquirir este lugar en virtud de la experiencia de Nina. Así pues, es "un género de çarça, que se suele plantar en los valladares de viñas y huertas para defender la entrada a los animales, y aun a los hombres, y de suyo nace en los erizados y tierras incultas (...) En Toledo ay una puerta que llaman del Cambrón, o se dixo por ser la entrada por aquella puerta agria y dificultosa". 
o borriqueras donde dormían los vagabundos que no podían pagar una casa de vecindad. Pero todavía no concluye la desolación y Nina no podrá menos que sentirse acongojada ante la visión del cuarto lóbrego de un anciano donde malvivían media docena de mendigos con sus respectivas proles, o el desolador cuadro que se le presenta cuando va a la maloliente casa de una mujer que llevaba en brazos un hijo disforme.

Quizás algo mejor (aunque no mucho), sea el espacio que Galdós destina a Obdulia como vivienda, un sotabanco cerca de la zona de los burreros, y que Carmen del Moral describe como residencia propia de los obreros: "...viven en los sotabancos o en las buhardillas de las casas habitadas por las demás clases, pero estas buhardillas, además de malsanas, porque son faltas de ventilación y estrechas, son caras"10. La casa de doña Francisca Juárez, modesta, pero con más solvencia, se verá sometida a un proceso de transformación tras haber recibido el dinero de la herencia. Pasa a ser una especie de jardín botánico, al que se le añaden pequeños objetos eminentemente burgueses, como puede ser la lámpara de araña que tanto fascinará a Nina. Todo ello da lugar a una mezcolanza de muebles pertenecientes a distintas clases sociales, algo que ya habíamos visto en la casa de las Porreño, en La Fontana de Oro. Finalmente la casa de don Carlos Trujillo, es la propia de una persona adinerada, con su despacho lleno de papeles, retratos u objetos de burgués ocioso, como pueden ser un reloj que no anda o un almanaque con la fecha pasada ${ }^{11}$. En este recorrido por las distintas casas de los personajes ya hemos podido darnos cuenta de que son un medio exclusivo para conocer el carácter de los protagonistas, pero también para saber la posición que ostentan o los cambios que han sufrido, a pesar de que la calle es el centro organizativo de la novela y no los espacios cerrados, como ocurre en otras novelas de Galdós.

Derivado de estas observaciones es el hecho de que en Misericordia podemos establecer otra dicotomía que funciona de manera operativa para distinguir personajes y también ambientes: esto es, la polaridad entre espacios abiertos y cerrados. Aquí los espacios cerrados se corresponden principalmente con las casas y también en ocasiones con las tabernas, pero no hay, como puede ocurrir con la sociedad burguesa, lugares para la sociabilidad como son el teatro, los casinos o los cafés. Pero aunque tengamos presentes estos espacios conclusos, la

10. MORAL, Carmen del, La sociedad madrileña, fin de siglo y Baroja, Madrid, Dirección General de Patrimonio Cultural, 1988, pág. 81.

11. "The instability of the social milieu can be observed in the edifices which Galdós often uses symbolically (...) Doña Paca's home also shows structural weakness (...) The darknes and squalor of the impoverished is described (...) Darknes fills the homes of even the rich: don Carlos's home is shrouded in black toile", Lois BAER BARR, "Social decay and desintegration in Misericordia", Anales galdosianos, año XVII, 1982, pág. 97-98. 
novela se desarrolla (y como no podía ser de otra manera) en espacios abiertos, en las calles y plazas de Madrid, con mendigos sin casa y personajes en perpetua peregrinación, frente a la clase media, como don Carlos y doña Paca, que suelen estar siempre dentro de sus hogares.

Algo como es el cambio de vivienda de doña Paca según avanza la acción de la novela, es, por último, lo más singular para demostrar el valor sociológico que tiene el vivir en unas calles u otras. Debido a la situación pecuniaria de la dama rondeña, muy de capa caída, ésta se verá obligada a pasar de la calle de Claudio Coello a la del Olmo, del Olmo al Saúco, del Saúco al Almendro y del Almendro a la calle Imperial ${ }^{12}$.

\section{El espacio simbólico}

I. En las novelas de Galdós, el elemento simbólico tiene bastante importancia, de manera que en cierto modo, supera los presupuestos realistas para crear unas composiciones mucho más complejas y ricas en la transmisión de ideas y sentimientos. Las casas y las calles madrileñas funcionan además a un nivel alegórico, a la vez que podemos reconocerlas en el Madrid real de la época. Igualmente, el desplazamiento de los personajes que en un principio puede parecer insignificante, trasciende de la realidad topográfica para pasar a formarse sobre una base completamente simbólica.

La crítica se ha ocupado de aspectos parciales de la simbología dentro de Misericordia, sobre todo en lo que se refiere a la relación con las intertextualidades bíblicas $^{13}$, de las que el texto está plagado. De un modo más marginal se han hecho observaciones acerca de lugares destacables en el ambiente de Nina, como son las escombreras donde se sitúa Almudena o bien la iglesia de San Sebastián. Lo cierto es que en ocasiones como esta resulta difícil el poder mantener separado el plano socio-histórico y simbólico, ya que se entrecruzan sin dejar resquicios para diferenciarlos.

12. "From the stately Calle Claudio Coello in the Barrio de Salamanca she is obliged to relocate to the successively poorer 'barrios' of Lavapiés (Calle del Olmo), Cuatro Caminos (Calle Saúco), Puerta Cerrada (Calle Almendro), and the Plaza Mayor (Calle Imperial). (...) Paca (...) moves yet again to a house on the prosperous Calle Orellana, a symbol of her financial solvency and her reintegration into decent society", Hazel GOLD, "Outsider art: homelessness in Misericordia", Anales Galdosianos, Año XXXVI, 2001, pág. 145.

13. BEARDSLEY, Th. S., "The life and passion of Christ in Galdós' Misericordia", en Homenaje a Sherman H. Eoff, 1970, pág. 39-58; CORREA, Gustavo, El simbolismo religioso en las novelas de Pérez Galdós, Madrid, Gredos, 1974; SCHRAIBAN, José, "Las citas bíblicas en Misericordia de Galdós", Cuadernos Hispanoamericanos, núm. 250-252 (1970-71), pág. 490-504. 
"Dos caras, como algunas personas, tiene la parroquia de San Sebastián" (pág. 71). Esta frase es la que permite ya desde el comienzo de la novela, dar una interpretación de la misma, de manera que podemos basarla en una serie de dualidades, como son las dos caras de la vida, una material, ocupada en el devenir de las cosas terrenales, y otra que se preocupa por la forma espiritual, por la vida del alma en el otro mundo. Esta disposición, como veremos más tarde, también aparece en otros aspectos relacionados con los movimientos de los personajes. Sin duda, este "edificio bifronte" también nos trae a la memoria el recuerdo de ese Jano, guardián de dos puertas, que mira hacia dos polos, como por otro lado mirará el señor don Carlos, que es un ejemplo viviente de la hipocresía de muchos de los burgueses y aristócratas que se veían en la obligación de socorrer a cuatro pobres para así satisfacer su fuero interno y su maltrecha conciencia y conseguir un pedazo de cielo en su viaje al más allá. Por supuesto, Nina escapa de todas estas dobleces del prójimo, ya que no hará distinción en llevar a casa de doña Paca a Frasquito Ponte o a Almudena.

Dentro de la iglesia, don Carlos Moreno recorrerá las distintas capillas, que de un modo más o menos simbólico nos arrojan luz acerca del carácter de este avaro redomado. Comienza con la capilla de Nuestra Señora de la Blanca, y continuará en el altar de los Dolores, suponiendo por el nombre que es una forma de penitencia, para pasar a la imagen de San Lesmes, que según explica García Lorenzo ${ }^{14}$, es un santo que murió de fatiga por repartir trigo entre los pobres, algo que resulta irónico si pensamos en un San Lesmes como don Carlos. Finalmente, el recorrido concluye "infaliblemente" en la capilla del Cristo de la Fe, punto culminante del proceso pseudo-místico.

También el simbolismo de los nombres de ciertos espacios es evidente cuando se trata por ejemplo de las calles, sobre todo en el caso de doña Paca y su constante emigración. Comienza pasando desde la calle Claudio Coello, situada en el barrio elegante de nueva creación de Salamanca, a la calle del Olmo, una zona del Madrid viejo. Hace toda esta mudanza dentro del mayor silencio para poder mantener las apariencias, aunque no tanto como para que la sociedad que le ayudó cuando poseía una fortuna, deje misteriosamente de visitarla. Tienen que buscar zonas más baratas, pasando a la calle del Saúco y después a la calle del Almendro (cerca de la Puerta de Moros), desapareciendo con este traslado las pocas amistades que le quedaban, hasta dar por fin y con toda la ironía amarga que su nombre comporta, en la calle Imperial, como dice el narrador, "buscando siempre baratura".

14. Luciano García Lorenzo ha interpretado el término 'blanca' como dinero ('estar sin blanca'), de manera que don Carlos le rezaría para que nunca le faltaría el dinero, aunque puede ser discutible (pág. 69 y siguientes). 
El propio narrador nos da pistas y juega con los nombres arbóreos de las calles al decir que la familia de doña Paca era como pájaros que van saltando de rama en rama, porque, al fin y al cabo, los están desplumando.

Tendrán una relevancia especial una serie de alusiones a ciertas zonas de Andalucía, que aunque en un principio pudieran parecer inocentes, evocan lo que Bajtín denominaría 'cronotopo idílico' ${ }^{15}$. Me refiero a la Villa de Ronda en Málaga, en una situación muy pintoresca, y de gran actividad comercial. Parece ser una zona donde residían esas rancias familias nobiliarias de título junto con otras enriquecidas por el comercio. Galdós se va a servir de la garganta 'Tajo' que divide Ronda en dos mitades y que mide doscientos metros para hacer una comparación con el carácter de doña Paca, no siendo inocente colocarla al borde de un abismo. Y dice así: "los nacidos en Ronda deben de tener la cabeza muy firme y no padecer vértigos ni cosa tal, hechos a contemplar abismos espantosos. Pero doña Paca no sabía mantenerse firme en las alturas: instintivamente se despeñaba; su cabeza no era buena para esto ni para el gobierno de la vida, que es la seguridad de vista en el orden moral" (pág. 103). Siempre que doña Paca hable de Ronda, lo hará como de un paraíso perdido, creando así un espacio mítico que se corresponde con un tiempo pretérito, en el que el dinero no era preocupación alguna y toda la vida era un sinfín de comodidades y abundancia, como en la Tierra de Jauja. Por eso, cuando hablen doña Paca y Ponte, que también es de Algeciras, "evocarán recuerdos de la tierra andaluza en que habían nacido, resucitando familias, personas y sucesos" (pág. 203).

II. No sólo van a ser los espacios estáticos los que cobren importancia a los ojos del lector sino que ciertos personajes van a estar en continuo movimiento, de manera que en ocasiones este ir y venir posee un carácter simbólico. Un caso digno de mención es el de Frasquito Ponte ${ }^{16}$, que recorre infatigable las calles de Madrid, en vista de que no tiene otra cosa mejor que hacer, pero se cuidará muy mucho por ejemplo de cruzar más allá de la Plaza Mayor, para que sus conocidos no le vean en su actual situación. Un acontecimiento cargado de humor y que no deja de ser simbólico es cuando el marido de Obdulia, Antonio y otros amigos van paseando en bici y a pie, mientras que Ponte, según su status, va a caballo.

15. Este concepto aplicado a la novela se encuentra en M. BAJTíN, "El cronotopo idílico en la novela", Teoría y estética de la novela, Madrid, Taurus, 1989, pág. 376-393.

16. Este caballero venido a menos, según su capacidad de creación de mundos fantásticos, nos puede traer a la memoria otros referentes galdosianos como es el personaje de Ido del Sagrario, también creador de ficciones dentro de la realidad. Ambos en última instancia nos remiten al soñador por excelencia: Don Quijote. 
Resulta paradójico que lo que se supone un rescate de aquella que se desvela por ellos, Nina, acabe convirtiéndose en una excursión de fin de semana. Considero significativo que ocurra el accidente del caballo de Ponte, que en cierto modo nos anuncia su trágico y ridículo final al caerse por las escaleras, cual un Calisto que sale del huerto de Melibea.

Sin embargo, en el devenir de la novela también se va a producir una evolución interior en el caballero rondeño, que no puede sustraerse a la caridad y bondad emanada por Nina. Unas acciones que son la salvación de Ponte cuando se encuentra fuera de sí, tanto físicamente como en lo referido al lugar social que le corresponde, así como todas las posteriores ayudas en lo que a alimentación se refiere, van haciendo mella, van abriendo los ojos y el corazón de Ponte a la luz divina, hasta que no puede menos que contarlo a los cuatro vientos, cuando llevado de un delirio mesiánico, proclama la santidad de Nina, y comprende, antes de su fatal muerte, la hipocresía que le rodea, la falta de aquello que representa Nina: misericordia. Obnubilado, la boca torcida, arrastrando la pierna, pronunciará estas palabras que son una forma de redención final, para él y para Nina:

"Me acusan de un infame delito: de haber puesto mis ojos en un ángel de blancas alas célicas, de pureza inmaculada. Sepan que yo respeto a los ángeles: si Nina fuese criatura mortal, no la habría respetado (...) La Nina no es de este mundo... La Nina pertenece al cielo (...) Mi hermosura es humana, y la de ella divina; mi rostro espléndido es de carne mortal, y el de ella de celeste luz..." (pág. 312)

Continúa despotricando contra doña Paca, pero es consciente del movimiento vertical en el que está, sabe que ahora, al comprender la verdad de Nina, puede subir al cielo, como una pluma, pero doña Paca, por una ingratitud consciente, que le remuerde la conciencia por más que quiera ocultarlo, se quedará en la tierra, porque es de plomo.

Obdulia tan sólo va a realizar un movimiento, que es el de su mudanza a un sotabanco con su marido Antonio, en el marco de una funeraria, que es simbólica para el caso de Obdulia, una romántica empedernida, bien porque es un lugar donde se puede disparar mejor la imaginación, bien porque es un lugar de momias, de elementos del pasado, como le ocurre a la hija de doña Paca, anclada en un tiempo pretérito fastuoso que ni siquiera ha conocido, quedando en un estado de momificación metafórico, como si fuera una niña embalsamada. A este respecto, cabe destacar la descripción de su casa, típica de Madrid, para lo cual Galdós empleará una técnica impresionista salpicada de toques irónicos. 
Los espacios que rodean a Almudena se caracterizan por tener una gran carga simbólica. Nos va a contar cómo se le apareció el rey Samdai del inframundo, que le dio para escoger entre un tesoro o una mujer bella y laboriosa. Mordejai optará por la mujer, pero tan sólo podrá verla de forma momentánea en un velo de sombras, lo cual le lleva a perseguirla por todo el mundo: Fez, Argelia, Tlemcén, Constantina, Orán, Marsella, Lyon, Dijon, París, Lille, Cette, Valencia... Nada más llegar a Madrid y oír la voz de Nina en la parroquia de San Sebastián, sabe que esa es la mujer que anda buscando y que le da la luz que necesita para su corazón. Armado pues de una gran paciencia, Almudena no sólo iniciará su peregrinar en busca de Nina, sino también en busca de la verdad, la virtud y el fuego de Dios simbolizado en Nina. Es una romería en la que Almudena se desprende de todas las riquezas y abundancia que hay en su tierra para cumplir este hecho espiritual.

Por eso, cuando todo el mundo haya dado la espalda a Nina, Almudena le insistirá para que juntos vuelvan a su tierra y se casen, para que vaya al edén terrenal donde no les faltará de nada. La descripción que hace Mordejai nos trae enseguida a la mente el paraíso idílico: "Casar migo tigo, y dirnos migo con tú a terra mía, terra de Sus. Mi padre Saúl, rico él; mis germanos, ricos ellos; mi madre Rimna, rica bunita ella... quierer ti, dicir hija ti... Verás terra mía: aceita mocha, laranjas mochas... carnieras mochas padre mío... mochas árbolas cabe el río; casa grande... noria d'agua fresca... bunito; ni frío ni calora" (pág. 212). Vemos que es un espacio completamente mítico, de manera que Almudena quiere concluir su viaje en Jerusalén, que es ciudad de Dios, donde se encuentra el sepulcro de los antepasados de Mordejai. Es también símbolo de la unión de las tres religiones que en su día poblaron España, y que ahora se vuelven a unir en paz y concordia a través de la amistad espiritual de Nina y Almudena.

Las claves religiosas nos van a ayudar también a comprender este episodio tan representativo como es la penitencia que Almudena hace en las escombreras de los arrabales madrileños y que posee una enorme carga simbólica. La acción se sitúa durante los días de Cuaresma, lo que en la religión mahometana lleva al ayuno y a la penitencia, que Almudena acompañará con los cantos roncos al son de la cítara. No debemos olvidar tampoco que esta actitud ascética está motivada también por el amor ciego que el mendigo siente hacia Nina. Schraibman ha sabido conectar muy bien todo este episodio con la simbología religiosa, relacionándolo con la palabra 'gehenna' ('infierno de los condenados'), que es lo que representaría la escombrera, y se refiere

"al Valle de Hinom, un valle al sudoeste de Jerusalén, notable como el lugar donde Ahaz introdujo a Israel la adoración del Dios pagano del fuego, Maloc, y donde se sacrificaban a niños (...) Debido a las reformas del rey Josías, los altares fueron destrozados y el valle fue hecho infame para 
siempre (...) Como consecuencia de ello, el valle de Hinom llegó a ser una escombrera pública que ardía todo tiempo y que criaba un gusano asqueroso difícil de matar". ${ }^{17}$

Pero no es necesario ir a historias tan desconocidas para nosotros para encontrar un simbolismo bíblico más cercano. Basta con mirar en el Libro de Job, 2, 8: "El Satán salió de la presencia de Yahveh, e hirió a Job con una llaga maligna desde la planta de los pies hasta la coronilla de la cabeza. Job tomó una tejoleta para rascarse, y fue a sentarse entre la basura". Son bastantes las concomitancias que podemos encontrar entre Job y Almudena, no sólo en lo que se refiere al espacio de los hechos narrados, puesto que esa basura era el montón de desperdicios que se colocaba a la salida del pueblo, como ocurre con el espacio de las Cambroneras. Tampoco podemos negar la paciencia que tuvo Mordejai para ir por todo el mundo en busca de su mujer ideal, o también que después se hagan realidad esas llagas por medio de la enfermedad que contraerá en la piel Almudena: la lepra. Otro dato que quizás sea sólo mera coincidencia, pero que no quiero dejar de notar es que Job es del país de Us, al Sureste del mar Muerto, y Almudena del país de Sus, en el Sahara occidental. ¿Casualidad esa cercanía fonética? Además, la imagen que se nos viene a la mente del ciego místico en medio de los despojos ya había sido utilizada por Galdós antes, concretamente en Fortunata y Jacinta, para de nuevo describir ese estado de enajenación que en este caso afectará a Mauricia la Dura:

\begin{abstract}
"En el opuesto lado de la huerta, que era el sitio más apartado y feo, había un tinglado, bajo el cual se veían tiestos vacíos o rotos, un montón de mantillo que parecía café molido, dos carretillas, regaderas y varios instrumentos de jardinería. En otro tiempo hubo allí un cubil, y en el cubil un cerdo que se criaba con los desperdicios; pero el Ayuntamiento mandó quitar el animal de Antón, y el cubil estaba vacío. Desde el anochecer se puso allí Mauricia la Dura, sola, sobre el montón de mantillo"18
\end{abstract}

Por último, el personaje que más movimientos realiza es Nina, a la que podríamos comparar con Celestina, en el sentido de unir distintos mundos sociales, el de los pobres y el de los nobles (aunque sean venidos a menos); eso sí, la finalidad de cada una de ellas es completamente distinta, pero en esencia se guían por una cosa: el amor, sólo que en el caso de Celestina es por interés económico y

17. SCHRAIBAN, art. cit., pág. 494-495

18. PÉREZ GALDÓS, Benito, Fortunata y Jacinta. Dos historias de casadas, ed. Francisco Caudet, Vol. I, Madrid, Cátedra, 1997, pág. 641. 
para un amor carnal, y en el caso de Nina, el amor es totalmente espiritual y no exige recompensación alguna. Otro personaje que se encuentra en el universo galdosiano y que pasa a convertirse en un guía urbano para el lector es el niño Luis de Miau, que ejerce un función espacial semejante a la de Nina.

Nina deambula constantemente de un sitio a otro, recorre todas las calles, callejuelas, tabernas, casas de dormir... con el fin de encontrar una "perra chica", tenaz en sus propósitos, sacrifica su bien propio, el pan de su boca, para ponerlo en manos de los demás. En ese ajetreo diario se nos aparece el movimiento de Nina como un discurrir por un laberinto material, pero que también lo es espiritual, de manera que tiene que salvar todos los espacios y recovecos que se le oponen en el camino, pero eso sí, no tratará de evitarlos. El suyo es un camino de sacrificio, un camino de perfección para imitar a Cristo, como han señalado los críticos, con unos claros paralelismos con la vida del Salvador. Así se establecen movimientos simbólicos como es el calvario de Nina que hará también descalza, llevando sus cruces y las de sus amigos, además de ser apedreada como Jesús, del modo más ingrato, pues los pobres de las Cambroneras, dejándose llevar, pedirán más y más a aquélla que lo da todo.

Nina se mueve entre dos espacios polarizados, el de cielo-tierra, o de forma más simbólica, cielo-infierno. Nuestra mendiga se encuentra en el mundo terrenal, pero con sus acciones de cada día logra alejarse de los bienes mundanos, lo que significa un acercamiento a la divinidad. Pero este momento no se da completo hasta el final abierto y esperanzador de la novela, cuando Nina es olvidada de los que ahora tienen dinero, y aunque al principio le invade la rabia y el dolor, sabe aceptar que ahora la ayuda debe seguir dándosela a otras personas que la necesiten más, como es el caso de Almudena. Triunfa así del mundo material, rompiendo los lazos que le unen a él, y con una mayor fortaleza espiritual, se siente más cerca de Dios y de su bondad suprema.

De nada sirve que sea encerrada en asilos como el de El Pardo, pues ella seguirá haciendo el bien. Y resulta completamente irónico que sea precisamente don Romualdo quien mande a Nina al Asilo de Misericordia ( $¡$ a ella, que es la misericordia y la caridad andantes!). Ella no puede estar encerrada, porque necesita espacios abiertos, lugares donde puede desarrollar su actividad benéfica, marcos que se abran al horizonte y que le muestren la infinitud que es el camino hacia Dios, porque ella va a seguir en esta vida ese camino que conduce al cielo, y sólo algunos de los que le rodean serán conscientes de que Nina ya ha alcanzado la "angelización" en vida, como Fortunata, que se transforma en ángel pero en el momento de su muerte. Nina ya lo ha conseguido antes de ese trance, y parece, según acaba la novela, que todavía le queda a la "dama de Dios" mucho por hacer, para demostrar a todo el mundo que ella es una auténtica santa. 
Las pruebas que tiene que pasar Nina van aumentando en un 'crescendo' narrativo, porque empieza por conseguir dinero para doña Paca, pero después se añaden a su espalda otros pesos, como Obdulia, incapaz de reaccionar a la realidad, o Frasquito Ponte; luego cargará con Almudena, lo que le lleva al encierro en el Hospicio. Es un claro Vía Crucis, que al final de la novela se transforma en redención, porque Juliana, la que ahora lleva el mando y los designios de la casa de doña Paca, se arrepiente, conoce su error y pide a Nina que le ayude, que le perdone.

III. Hay unos espacios simbólicos divinos que recorren toda la novela, y es la ya mencionada distinción de cielo e infierno. En varias ocasiones, tenemos ejemplos de lo que podríamos llamar un "descenso a los infiernos", que sobre todo es evidente cuando Nina hace su recorrido para llegar a las Cambroneras en busca de Almudena, y vamos viendo a través de sus ojos las mayores inmundicias y los espectáculos más degradantes ${ }^{19}$. Ése es el verdadero infierno, ya que en el otro plano se podría considerar que la progresiva degeneración social de doña Paca, también constituye una "bajada a los infiernos", pero como muy bien dice ella, no es así, y se queda rezando, mientras Nina va en busca de algún medio con el que poder pagar las deudas de su señora, "a todos los santos del cielo para que te inspiren, y a las dos nos saque de este Purgatorio" (pág. 189). Vemos así que doña Paca está mal, pero no tanto como pueda suceder con los pobres desheredados. El plano celeste no tiene una representación física en la novela, pero está continuamente aludido como destino final de las personas, y que algunos, como don Carlos, quieren conseguir a fuerza de dinero, mientras que Nina no se lo plantea como un destino final, sino que poco a poco se va haciendo el camino que le conducirá al cielo, a través de sus obras y de su confianza plena en Dios.

IV. Otra forma de espacialización que resulta muy interesante, pero en la que no me voy a detener, puesto que ya ha sido bastante estudiada por los galdosianos, es la división que podemos hacer entre realidad y ficción, o realidad y sueño, que preside toda la novela. Nina se erige como una guardiana de esta realidad-sueño, y su capacidad creadora llegará a un punto increíble de confusión. En un mundo tan horrible como es el de la mendicidad, Galdós busca el contraste a través

19. Este infierno está también espacialmente vinculado al caos que puede percibirse en las construcciones de las casas y las calles de los barrios del sur, así como en las propias gentes que las habitan, lo cual nos retrotrae al mundo de lo carnavalesco. Aquí entra en juego el concepto 'locura del texto urbano', que según Margarita O'BYRNE CURTIS (art. cit.), implica una dialéctica entre una tendencia al orden y la armonía y otra que presenta la confusión como paradigma. 
de otros personajes capaces de crearse mundos ficticios de ensoñación en los que tratan de hacer su vida y así sustraerse a la realidad circundante (Obdulia, Paca y Ponte).

Creo que todo lo que se ha visto hasta ahora sirve para establecer una estrecha relación entre el perfil que traza Galdós de sus personajes y el espacio en el que se desenvuelven, de manera que es una característica inherente a ellos. Así, a la luz de los lugares por los que se van moviendo los protagonistas podemos sacar en claro muchos rasgos que nos sirven, no sólo para dibujar el carácter inicial de los mismos, sino también las posteriores evoluciones que se dan en ellos merced a sus viajes o traslados. Sin duda nos encontramos ante un universo de personas que se encuentran en un continuo movimiento, pero además éste es reflejo de unas vivencias únicas e irrepetibles que sirven para cambiar su forma de pensar, de vivir la vida e incluso de preparar su muerte. Considero que este es un aspecto capital para poder entender la obra de Galdós en todas sus dimensiones, porque si no estaríamos de algún modo faltos de una visión global, que aúne todos los elementos con el fin de crear una historia mucho más trabada y unos personajes que nos resultan cercanos gracias a esa unión de un espacio socio-histórico claramente representativo y un espacio simbólico que nos da aquellos datos que nos faltan para completar una perspectiva total, y por qué no, realista, de las historias que se nos han contado.

\section{Bibliografía}

ANDERSON, Farris. Espacio urbano y novela: Madrid en Fortunata y Jacinta. Madrid: Porrúa Turanzas, 1985.

— "Madrid y el espacio de Miau". Cuadernos Hispanoamericanos, 1993, 521, p. 23-36.

BACHELARD, Gaston. La poética del espacio. México: Fondo de Cultura Económica, 1992.

BAER BARR, Lois. "Social decay and desintegration in Misericordia". Anales galdosianos, 1982, 17, p. 97-98.

BAJTÍN, M. "El cronotopo idílico en la novela". Teoría y estética de la novela. Madrid: Taurus, 1989, p. 376-393.

BAKER, Edward. "En el café de Galdós: La Fontana de Oro". Materiales para escribir Madrid: literatura y espacio urbano. Madrid: Siglo XXI, 1991. 
BEARDSLEY, Th. S. "The life and passion of Christ in Galdós' Misericordia". En: Homenaje a Sherman H. Eoff. Madrid: Castalia, 1970, p. 39-58.

CAPMANY, A. Origen histórico y etimológico de las calles de Madrid. Madrid: Imprenta de Manuel B. de Quirós, 1863.

CASALDUERO, Joaquín. "Significado y forma de Misericordia". En: Vida y obra de Galdós (1843-1920). 4ª ed. Madrid: Gredos, 1974.

CORREA, Gustavo. El simbolismo religioso en las novelas de Pérez Galdós. Madrid: Gredos, 1974.

CHUECA GOITIA, Fernando. "La ciudad galdosiana". Cuadernos Hispanoamericanos, 1970 - 1971, 250-252, p. 85-108.

GOLD, Hazel. "Outsider art: homelessness in Misericordia". Anales Galdosianos, 2001, 36, p. 145.

GULLÓN, Ricardo. Galdós, novelista moderno. Madrid: Gredos, 1960.

HIDALGO, Ramón. Madrid galdosiano. Madrid: La Librería, 1990.

LÓPEZ-LANDY, Ricardo. El espacio novelesco en la obra de Galdós. Madrid: Centro Iberoamericano de Cooperación, 1992.

Madrid en Galdós, Galdós en Madrid. Madrid: Dirección General de Patrimonio Cultural, 1988.

MESONERO ROMANOS, Manuel. "El arte en las iglesias de Madrid. San Sebastián". La Ilustración Española y Americana, 8 de diciembre de 1914, 45, p. 350.

MORAL, Carmen del. La sociedad madrileña, fin de siglo y Baroja. Madrid: Turner, 1974.

O'BYRNE CURTIS, Margarita. "Madrid o la locura del 'texto' urbano: la representación de la ciudad en la narrativa galdosiana". En: VIDAL TIBBITTS, M. (Ed.). Studies in honor of Gilberto Paolini. Newark (Delaware): Juan de la Cuesta, 1996, p. 195-206.

PÉREZ GALDÓS, Benito. 'Madrid', "Guía espiritual de España". Obras completas. Novelas III / Miscelánea. Madrid: Aguilar, 1977.

- Misericordia. Edición de Luciano García Lorenzo. Madrid: Cátedra, 1998.

PEÑASCO, H. y P. CAMBRONERO. Las calles de Madrid. Noticias, tradiciones y curiosidades. Madrid: Administración, 1889.

PLA, Carlos et al. El Madrid de Galdós. Madrid: El Avapiés, 1987.

RÉPIDE, Pedro de. Madrid: Madrid: La Librería, 1971.

SAINZ DE ROBLES, Federico C. El Madrid de Galdós, o Galdós, uno de los Cuatro Grandes, no madrileños de Madrid. Madrid: Instituto de Estudios Madrileños, 1967.

SCHRAIBAN, José. "Las citas bíblicas en Misericordia de Galdós". Cuadernos Hispanoamericanos, 1970 - 1971, 250-252, p. 490-504.

ULLMAN, Pierre L. "A contrapuntal and Spenglerian approach to Misericordia", Hispanic Review, 1992, 60 (3), p. 321-339.

ZAMBRANO, María. La España de Galdós. Barcelona: Laila, 1982. 
